\title{
Protein Kinase C Alteration Is an Early Biochemical Marker in Alzheimer's Disease
}

\author{
E. Masliah, ${ }^{1}$ G. M. Cole, ${ }^{1}$ L. A. Hansen, ${ }^{1}$ M. Mallory, ${ }^{1}$ T. Albright, ${ }^{1}$ R. D. Terry, ${ }^{1}$ and T. Saitoh ${ }^{1,2}$ \\ ${ }^{1}$ School of Medicine, Department of Neurosciences and ${ }^{2}$ Center for Molecular Genetics, University of California at San \\ Diego, La Jolla, California 92093-0624
}

\begin{abstract}
Neuritic (senile) plaques are a hallmark of the pathology found in the brain of patients afflicted with Alzheimer's disease (AD). Neuritic plaques have been considered to be composed of an amyloid core surrounded by dilated neurites, although the use of anti- $\beta / A 4-p r o t e i n$ antibody revealed the presence of diffuse plaques without a nuclearlike central mass or surrounding paired helical filament (PHF)-containing neuritic components. The presence of diffuse plaques without PHF-containing neuritic components strongly suggests that the formation of amyloid precedes the degeneration of neurites that surround amyloid. Diffuse plaques are thus considered to be an early marker of $A D$ pathology. In this article, we report that diffuse plaques, possible markers of early AD pathology, are immunostained with anti-protein kinase $C(\beta I I)$ [anti-PKC $(\beta I)]$ antibodies. The PKC $(\beta \mid 1)$-immunoreacting components of the diffuse plaques extend from neurons embedded in the plaques. Immunoelectron microscopy of diffuse and mature neuritic plaques shows that PKC $(\beta$ II)-like immunoreactivity in the plaques is closely associated with membranous structures of fine neuronal processes apposed to the amyloid fibers. These fine neuronal processes are distinct from classical neurites found typically in mature neuritic plaques. Furthermore, biochemical analysis demonstrates that PKC abnormalities, but not other AD markers (ubiquitin and A68), were found in the neocortex of clinically nondemented individuals with cortical plaques. Therefore, the PKC alteration in neurons might be involved in the early pathophysiology of AD.
\end{abstract}

Understanding the early pathogenesis of Al7heimer's disease (AD) is of vital importance in developing a therapeutic strategy for intervention in this devastating disease. One clue might come from the study of diffuse plaques, suspected of being the earliest type of plaque in AD (Mann and Esiri, 1988; Tagliavini et al., 1988; Yamaguchi et al., 1988, 1989; Giaccone et al., 1989; Ikeda et al., 1989; Ishii et al., 1989; Joachim et al., 1989; Motte and Williams, 1989; Ogomori et al., 1989). Until recently, neuritic (senile) plaques have been considered to be composed of an amyloid core surrounded by dilated neurites (Wisniewski and

\footnotetext{
Received Jan. 21, 1991; revised Apr. 1, 1991; accepted Apr. 3, 1991.

We acknowledge Drs. A. Haas and P. Davies for their generous gift of antiubiquitin and Alz-50, S. Ovadia for technical assistance with the color photography, and $\mathrm{R}$. Davignon for editorial help in manuscript preparation. This work was supported by grants from the McKnight Endowment Fund for Neuroscience the Pew Charitable Trust, the Alzheimer's Disease and Related Disorders Association, and the National Institutes of Health (AG05131, AG08201, and AG08205).

Correspondence should be addressed to T. Saitoh, Department of Neurosciences (0624), UCSD, La Jolla, CA 92093-0624.

Copyright (C) 1991 Society for Neuroscience $0270-6474 / 91 / 112759-09 \$ 03.00 / 0$
}

Terry, 1973). The use of anti- $\beta /$ A4-protein antibody, however, revealed the presence of diffuse plaques without a nuclear-like central mass or surrounding paired helical filament (PIIF)-containing neuritic components, changing the definition of neuritic plaques (Tagliavini et al., 1988; Yamaguchi et al., 1988, 1989; Giaccone et al., 1989; Ikeda et al., 1989; Ishii et al., 1989; Joachim et al., 1989; Motte and Williams, 1989; Ogomori et al., 1989). Anti- $\beta /$ A4-protein antibody stains the amyloid core of classic plaques, burned-out plaques, the diffuse amyloid of primitive plaques, and diffuse plaques. The systematic study of Mann and Esiri (1988) demonstrated that brains of early-stage Down's syndrome patients contain diffuse plaques, those of intermediate-stage brains contain immature plaques, and those of advanced-stage brains contain mature plaques, suggesting that diffuse plaques are precursors of mature plaques. To shed light on the mechanisms of early plaque formation, we have examined diffuse plaques using immunoprobes for plaque-associated markers, including protein kinase $\mathrm{C}$ (PKC), which has recently been found, in nondemented and demented autopsy cases, to be associated with mature plaques (Masliah et al., 1990). Diffuse plaques were found to be immunoreactive with antibodies against $\mathrm{PKC}(\beta \mathrm{II})$, but not other markers, including other PKC isozymes, casein kinase II (CK-II), tau, and PHF, suggesting that the PKC $(\beta I I)$ might be involved in an early stage of plaque formation. Furthermore, reduced levels of the particulate PKC $(\beta \mathrm{II})$ concentration and of PKC-dependent $M_{r} 86,000$ protein (P86) phosphorylation, but no increased levels of Alz50 reactivity or anti-ubiquitin reactivity, were found in the neocortex of demented and nondemented autopsy cases with diffuse plaques. These results suggest that altered PKC reactions may be early changes in AD.

\section{Materials and Methods}

Biochemistry. Procedures for sample preparation and the in vitro phosporylation assay are described in a previous publication (Cole et al., $1988)$. PKC $(\beta I I)$ was quantified using Western blot as described previously (Masliah et al., 1990). The anti-PKC $(\beta I I)$ antibody was raised in rabbit against the keyhole limpet hemocyanin-conjugated peptide whose sequence was taken from the $\mathrm{C}$-terminal portion of human PKC $(\beta I I)$. The specificity and characterization of anti-PKC $(\beta \mathrm{II})$ antibody are given in a previous publication (Masliah et al., 1990). In brief, this antibody stained an $M_{r} 80,000$ protein, conceivably $\mathrm{PKC}$, on a Western blot of human brain homogenate and stained the synaptic boutons around Purkinje cells and their dendrites in human cerebellar sections. These stainings were adsorbed out by preincubation of the antibody with the PKC $(\beta I I)$ peptide but not with irrelevant peptides, suggesting the specificity of the staining. The $\mathrm{C}$-terminal sequence of PKC $(\beta I I)$ used to immunize rabbits is not found in any other PKC isozymes, further implying the specificity of the staining. Ubiquitin- and Alz-50-reactive material was quantified using an immunodot blot pro- 

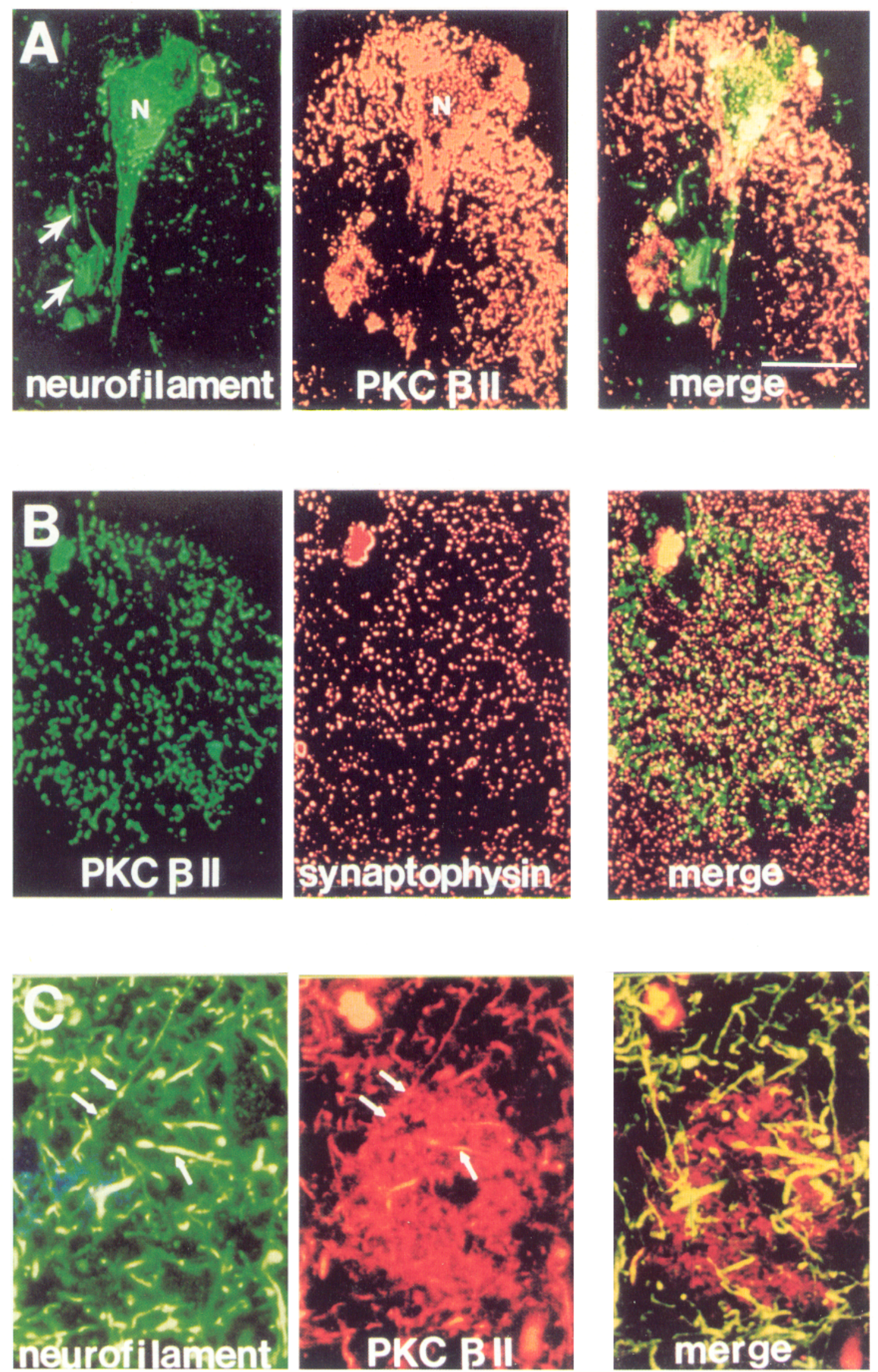

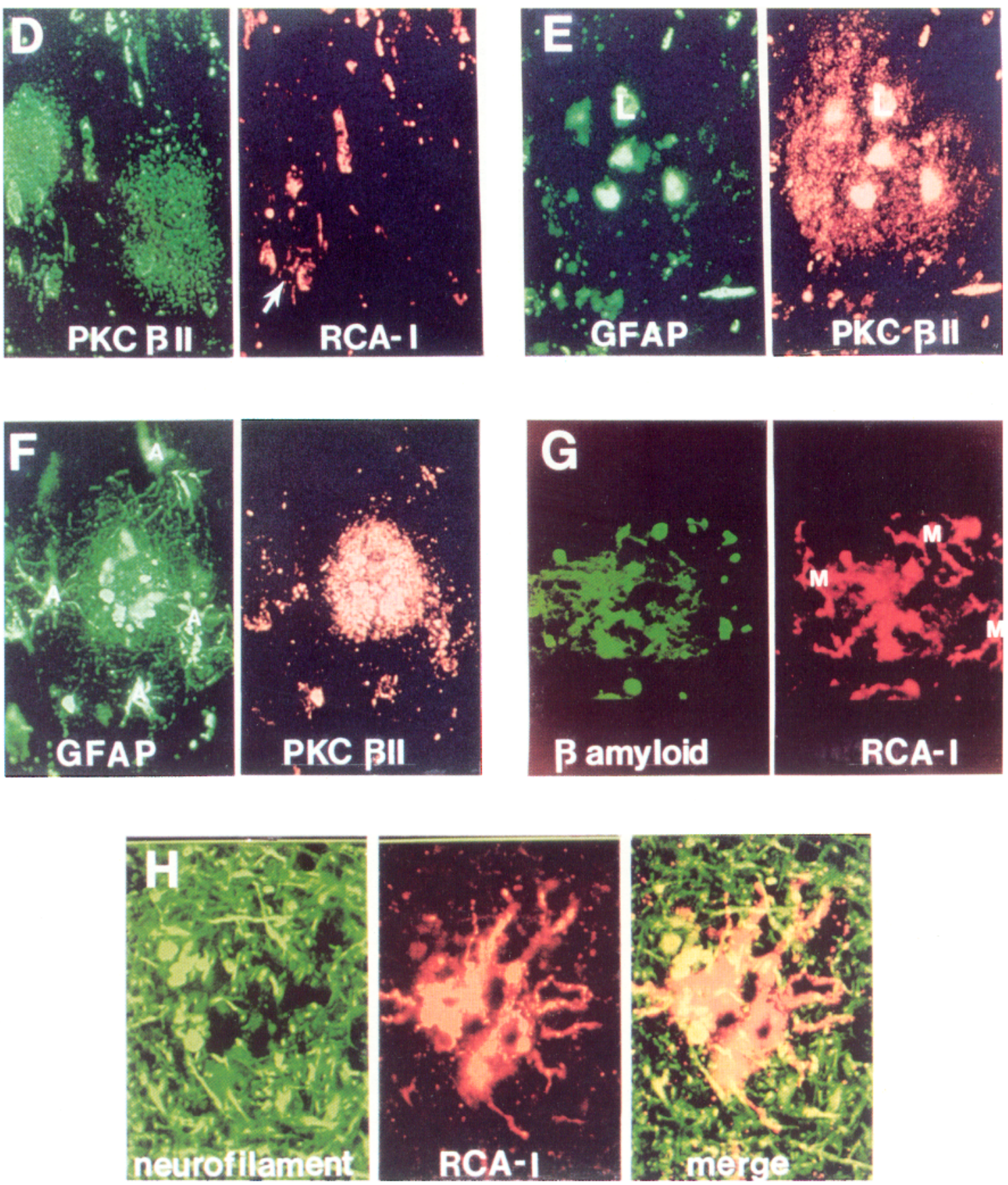

Figure 1. Diffuse plaques are immunostained with PKC( $\beta$ II). Laser confocal imaging was used to view the double-labeled sections. The image in green corresponds to the FITC channel, and the image in red, to the Texas Red channel. $A$, An SMI-31 (neurofilament)-immunostained pyramidal neuron $(N)$ and neuritic processes (arrows) display extensive PKC $(\beta I I)$ immunolabeling around the cell body and extend diffusely into the neuropil. $B$, The PKC $(\beta I I)$-labeled neuropil in a diffuse plaque shows the presence of anti-synaptophysin-labeled presynaptic terminals. $C$, Anti-SMI-31positive neuritic processes (arrows), immersed in a PKC $(\beta \mathrm{II})$-positive diffuse plaque, are colocalized with PKC( $\beta$ II)-positive neuritic processes (arrows) in the diffuse plaque. $D$, Anti-PKC $(\beta \mathrm{II})$-positive diffuse plaques do not show an association with RCA-1-positive microglial processes (arrow). $E$, No anti-GFAP-positive processes can be observed in a PKC( $\beta$ II)-positive diffuse plaque that is surrounding lipofuscin $(L)$-containing neurons. $F$, Abundant GFAP-positive astrocytic processes $(A)$ are observed in a PKC $(\beta I I)$-positive mature plaque. $G$, Abundant RCA-1-positive microglial processes $(M)$ are observed in relation to an anti- $\beta$ /A4-protein-positive mature plaque. $H$, No colocalization of neuritic and microglial processes is observed in a mature plaque. Scale bar, $15 \mu \mathrm{m}$.

cedure described previously (Love et al., 1988). Anti-ubiquitin and Alz50 are the generous gifts of Dr. A. Haas (NYU, Medical Center) and Dr. P. Davies (Albert Einstein College of Medicine), respectively. Fourteen brains from clinically nondemented $[73 \pm 9$ yr; postmortem $(\mathrm{PM})$ time, $7 \pm 6 \mathrm{hr}$ ] cases and 15 brains from AD cases $(76 \pm 7 \mathrm{yr}$; PM time, $5 \pm 4 \mathrm{hr}$ ) were used for the present study. Brains were sagittally cut, and the left hemibrains were fixed in $4 \%$ phosphate-buffered for- malin for fewer than $10 \mathrm{~d}$, while the right hemibrains were frozen for biochemical assay. The fixed brains were processed and examined for plaques and tangles as described previously (Terry et al., 1987). Four brains from nondemented cases contained moderate numbers of cortical plaques. Five brains from AD cases contained few neocortical tangles, whereas abundant hippocampal tangles and numerous cortical plaques confirmed the diagnosis of $\mathrm{AD}$. 

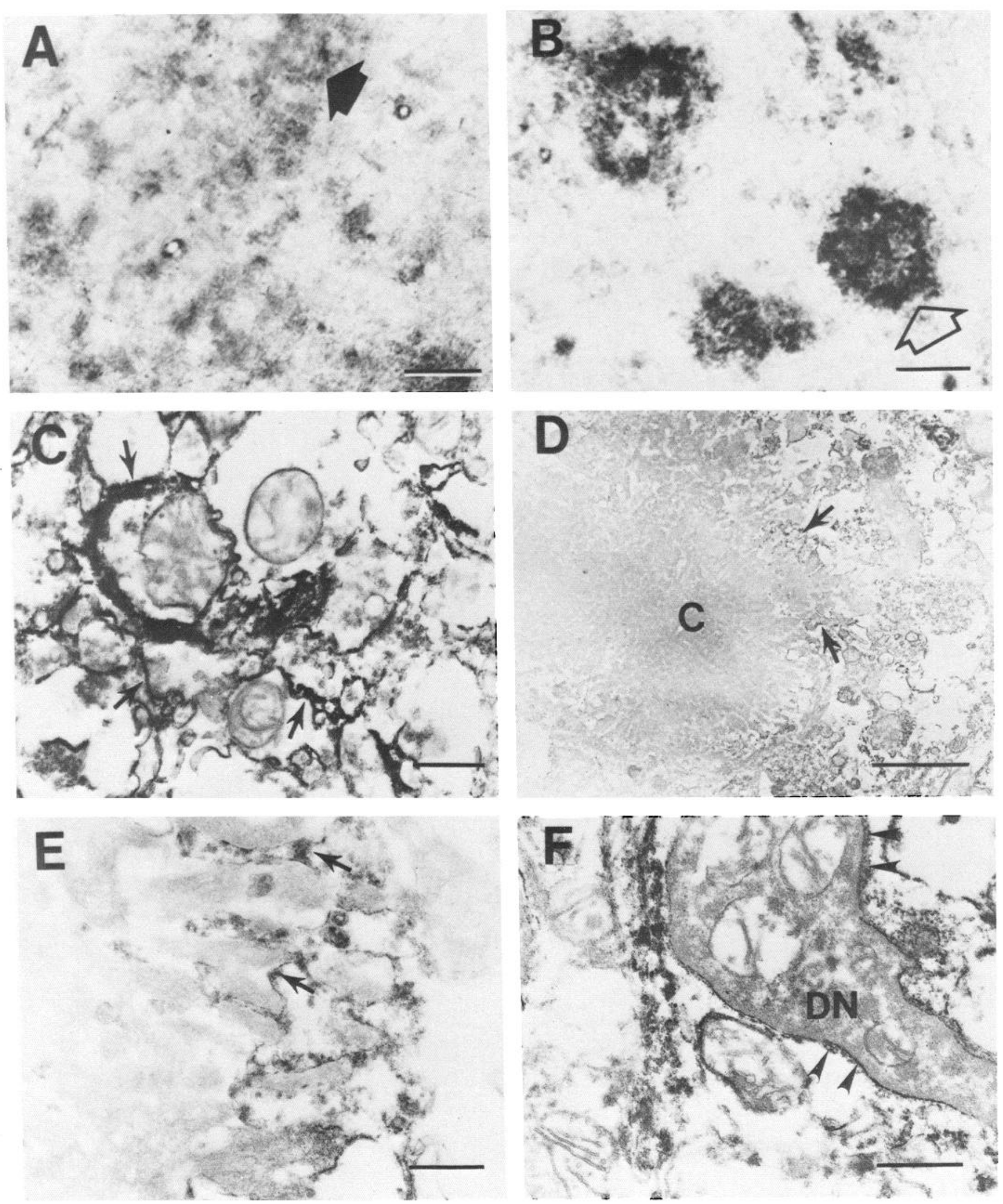

Figure 2. Immunoelectron microscopy reveals the membrane localization of PKC( $\beta \mathrm{II}) . A$ and $B$, Vibratome sections immunostained with antiPKC $(\beta \mathrm{II})$, developed with DAB, and viewed with a light microscope, showing examples of different types of plaques: diffuse (arrow) and mature (open arrow). C, At the ultrastructural level, the diffuse plaques presented PKC( $\beta$ II)-positive material associated with the membrane of cellular processes (arrows). $D$, Mature plaque with a dense amyloid core $(C)$ shows positive membranous processes (arrow) attached to the amyloid fibers. $E$, Higher magnification of the image in $D$. Arrows present PKC $(\beta \mathrm{II})$-positive material. $F$, Dystrophic neurites $(D N)$ in a mature plaque present darkly labeled PKC( $\beta \mathrm{II})$-positive membranes (arrowheads). Scale bars: $A$ and $B, 20 \mu \mathrm{m} ; C, E$, and $F, 1 \mu \mathrm{m} ; D, 5 \mu \mathrm{m}$. 
Immunohistochemistry. Laser confocal imaging was used to view the double-labeled sections. For immunohistochemistry, blocks from autopsy tissue of four controls $(71 \pm 11 \mathrm{yr}$; PM time, $5 \pm 3 \mathrm{hr})$ and four AD cases $(75 \pm 10 \mathrm{yr}$; PM timc, $6 \pm 1 \mathrm{hr}$ ) from the midfrontal cortex and the posterior hippocampus were fixed for $72 \mathrm{hr}$ at $4^{\circ} \mathrm{C}$ in $2 \%$ paraformaldehyde (in PBS, $\mathrm{pH} 7.4$ ). The tissue blocks were sectioned at 40 $\mu \mathrm{m}$ with an Oxford vibratome. The sections were double labeled overnight at $4^{\circ} \mathrm{C}$ with a mixture of the following antibodies or marker: (1) anti-PKC $(\beta I I) /$ anti-neurofilament (neuronal marker; SMI-31, Sternberger-Meyers Immunocytochemicals, Inc., Jarrettsville, MD), (2) antiPKC $(\beta \mathrm{II})$ /anti-synaptophysin (presynaptic terminal marker; Boehringer Mannheim, Indianapolis, IN), (3) anti-PKC $(\beta I I) /$ biotinylated RCA-1 (microglial marker; Vector Labs, Inc., Burlingame, CA), and (4) antiPKC( $\beta \mathrm{II})$ /anti-glial fibrillary acidic protein (GFAP; astrocytic marker; Boehringer Mannheim, Indianapolis, IN). Additional sections were double immunolabeled with anti-amyloid $\beta / \mathrm{A} 4$ protein and anti-synaptophysin, SMI-31, or RCA-1. The sections were then incubated with a combination of secondary antibodies or avidin tagged with fluorescein isothiocyanate (FITC) or Texas Red (Vector Labs, Inc). The doublelabeled sections were transferred to gelatin-coated slides and mounted under glass coverslips with antifading medium (4\% $n$-propyl gallate; Sigma Chemical Co., St. Louis, MO). The double-labeled vibratome sections were studied with the Bio-Rad MRC-600 laser confocal scanning microscope mounted on a Nikon Optiphot microscope. This system permits the simultaneous analysis of double-labeled samples in the same optical plane. The digitized video images of serial $1-\mu \mathrm{m}$ optical sections were stored on an optical disk for subsequent processing and analysis.

Electron microscopy. Vibratome sections were blocked with normal goat serum $(5 \%)$ and incubated overnight at $4^{\circ} \mathrm{C}$ with anti-PKC $(\beta \mathrm{II})(1$ : $35)$. The sections were washed in PBS, incubated with biotinylated goat anti-rabbit IgG followed by avidin D-IIRP (Vector ABC Elite), and reacted with diaminobenzidine (DAB; $0.2 \mathrm{mg} / \mathrm{ml}$ ) in $50 \mathrm{~mm}$ Tris buffer (pH 7.4) with $0.001 \% \mathrm{H}_{2} \mathrm{O}_{2}$. Control sections were incubated with preimmune serum. The immunostained sections were postfixed for 20 min in $1 \% \mathrm{OsO}_{4}$, dehydrated, and flat embedded in epoxy/Araldite. Ultrathin sections were cut with a Reichert OM-U3 ultramicrotome and viewed with a $100 \mathrm{CX}$ JEOL electron microscope.

\section{Results}

Confocal laser imaging of the control sections, reacted with antiPKC $(\beta I I)$, showed immunolabeled neuronal perikarya and neuritic extensions of pyramidal cells in layers III and V of the frontal cortex and in the CA1 to CA4 region of the hippocampus. In addition, occasional fine cellular processes were labeled in the neuropil and in the white matter. Some pyramidal cells in the $\mathrm{AD}$ cases were labeled with anti-PKC $(\beta I \mathrm{I})$, and the prominently labeled amyloid plaques were distributed throughout the ncuropil. Approximately $60-70 \%$ of the plaques were of the diffuse type and were mostly distributed in the superficial layers. The immature and mature neuritic plaques were also anti$\mathrm{PKC}(\beta \mathrm{II})$ positive and were found in the deeper layers of the neocortex. In the hippocampus the anti-PKC $(\beta \mathrm{II})$-immunoreactive plaques were distributed in the molecular layer of the dentate gyrus and in the entorhinal cortex. Anti-PKC $(\beta I I)$ stained diffuse plaques as a fine granular or fibrillar mesh of cellular processes in the hippocampus and neocortex (Fig. $1 A$ ). Neuronal perikarya were often found in the midst of the diffuse plaques (Fig. $1 E$ ). Double-immunolabeled sections showed that the anti$\mathrm{PKC}(\beta \mathrm{II})$-immunoreacting processes contained abundant antineurofilament (SMI-31)-positive fibers (Fig. 1C). Serial optical sections along the whole thickness of the diffuse plaques revealed a continuum between the $\mathrm{PKC}(\beta \mathrm{II}) / \mathrm{SMI}-31$-positive processes and the neuronal perikarya (Fig. $1 A$ ). Sections were also double immunolabeled with anti-PKC $(\beta \mathrm{II}) /$ anti-synaptophysin (presynaptic terminal marker). The neuropil harboring the $\mathrm{PKC}(\beta \mathrm{II})$ labeled diffuse plaques revealed the presence of anti-synaptophysin-labeled terminals (Fig. $1 B$ ). The AD sections that were double labeled with anti-PKC $(\beta \mathrm{II}) /$ anti-GFAP and anti-
PKC $(\beta$ II $) /$ RC.A-1 failed to show any association between the $\operatorname{PKC}(\beta \mathrm{II})$-positive processes in the diffuse plaques and cellular processes of astrocytes (Fig. $1 E$ ) or microglia (Fig. $1 D$ ). In contrast, in immature and mature plaques, abundant numbers of astrocytic and microglial processes were found to be closely associated with the anti-PKC $(\beta \mathrm{II})$ - and anti- $\beta / \mathrm{A} 4$-protein-positive structures (Fig. $1 F-H$ ).

At the ultrastructural level, the $\mathrm{PKC}(\beta \mathrm{II})$-positive material was closely associated with the membrane of fine cellular processes immersed in the plaques (Fig. 2).

In vitro phosphorylation of $\mathrm{P} 86$ in the presence of $\mathrm{PKC}$ activators has been found to be diminished in the cytosolic fractions from AD cortex (Cole et al., 1988). In the present study, P86 phosphorylation was studied in four different groups of samples. The first group $(N=8)$ consisted of the nondemented cases without any plaques in the cortex. The second group ( $N$ $=4$ ) contained the nondemented cases with some plaques in the cortex. The third group $(N=7)$ encompassed the AD patients with a moderate number of cortical plaques. The fourth group $(N=7)$ included the AD patients with numerous cortical plaques. The P86 phosphorylation in the second, third, and fourth groups was diminished as compared to the first group (one-way $t$ test; $p<0.02, p<0.001, p<0.0005$, respectively), with the trend toward the more pronounced changes in cases with more plaques (Fig. 3A). The same cases were then reclassified according to tangle numbers. This time, the first group $(N=12)$ contained the nondemented cases without neocortical tangles. The second group $(N=5)$ included the AD samples with few neocortical tangles. The third group $(N=4)$ held the AD samples with a moderate number of tangles, and the fourth group $(N=5)$ had the AD samples with numerous tangles. Irrespective of the presence or absence of tangles, AD cases had lower levels of P86 phosphorylation than nondemented controls (Fig. 3B). Therefore, decreased P86 phosphorylation correlated with plaque counts but not with neurofibrillary tangle counts. The diminished P86 phosphorylation was thus observed in nondemented cases with plaques.

In $\mathrm{AD}$ frontal cortex, $\mathrm{PKC}(\beta \mathrm{II})$ is severely affected in that the particulate enzyme is diminished and the soluble enzyme is increased as detected by Western blots, and the number of neurons stained with anti-PKC $(\beta \mathrm{II})$ is diminished by $80 \%$ (Masliah et al., 1990). The concentration of $\mathrm{PKC}(\beta \mathrm{II})$ in the frontal cortex particulate fraction was studied and averaged for eight different classes of samples as described for P86 phosphorylation. The results for $\mathrm{PKC}(\beta \mathrm{II})$ were qualitatively the same as for P86 phosphorylation (Fig. $3 C, D$ ); the $\mathrm{PKC}(\beta \mathrm{II})$ alteration seemed to correlate with the presence of plaques and not with tangles. Other PKC isozymes in particulate fractions were not significantly affected in AD cortex.

Two other biochemical changes found in AD, increased levels of ubiquitin and Alz-50 antigen, were studied in eight classes of samples (Fig. $3 E-H$ ). In contrast to P86 phosphorylation or anti-PKC $(\beta \mathrm{II})$ immunoreactivity, nondemented individuals with cortical plaques did not have altered levels of ubiquitin or Alz50 antigen. The levels of these markers were higher in AD samples relative to control samples, irrespective of the presence or absence of tangles and plaques.

\section{Discussion}

The present study raises the possibility that an altered PKCdependent phosphorylation may be involved in an early stage of plaque formation. There are two lines of evidence that support 
Figure 3. In vitro phosphorylation of P86 and the levels of particulate PKC $(\beta I I)$ are diminished in AD and in nondemented cases with plaques, whereas the levels of ubiquitin- and Alz50-reactive material were not altered in nondemented cases with plaques. $A$ and $B$, P86 phosphorylation expressed as the percentage of total phosphorylation; $C$ and $D, \mathrm{PKC}(\beta \mathrm{II})$ immunoreactivity; $E$ and $F$, anti-ubiquitin immunoreactivity; $G$ and $H$, Alz-50 reactivity. Various biochemical markers quantified as described in the previous publications (Cole et al., 1988; Love et al., 1988; Masliah et al., 1990) are plotted for four categories of cases. The number of cortical plaques in a $100 \times$ field is shown as $-(0),+(1-10),++(11-49)$, and $+++(>50)$. The number of cortical tangles in a $400 \times$ field is shown as $(0),+(1-2)$, and $++(>3)$. Horizontal bars indicate means.
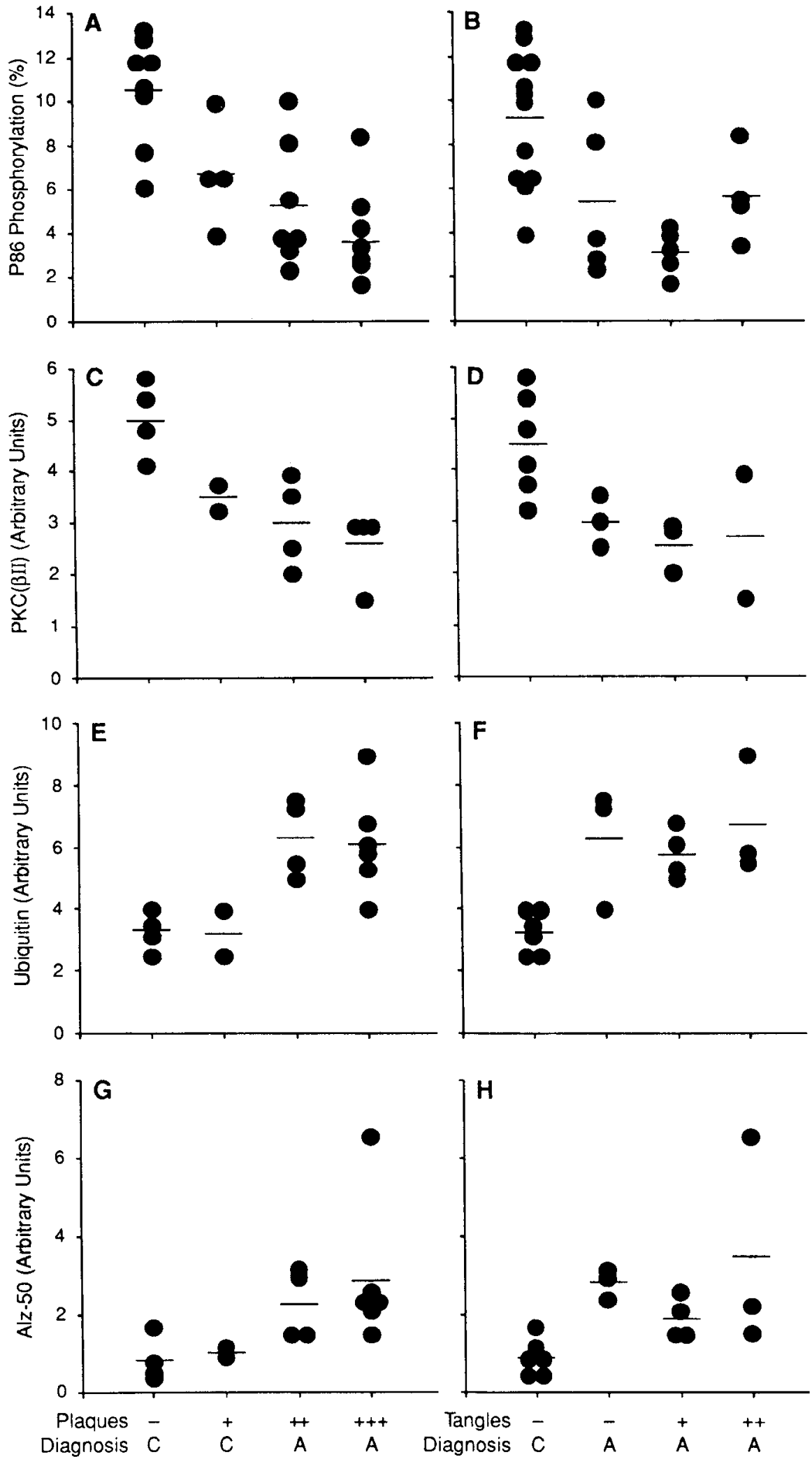

this theory. First, diffuse plaques, which precede the appearance of classical AD plaques, displayed anti-PKC $(\beta \mathrm{II})$ immunoreactivity. Second, the reduced levels of particulate PKC $(\beta I I)$ and the diminished PKC-dependent P86 phosphorylation were found in the cortex of clinically nondemented individuals with cortical diffuse plaques. The levels of two other $\mathrm{AD}$ biochemical markers, ubiquitin and Alz-50 antigen, were not elevated in nondemented cases with cortical plaques, suggesting that, relative to PKC, they are involved in a later stage of AD pathogenesis. It is therefore possible that $\mathrm{PKC}$-related alterations are age-asso- 
A

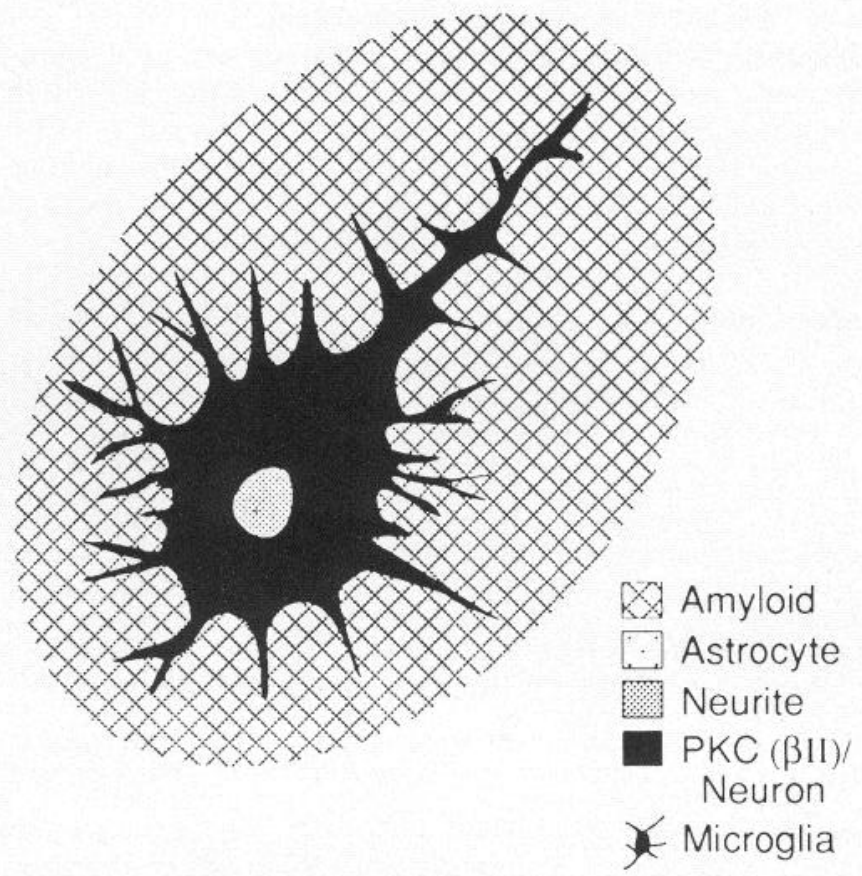

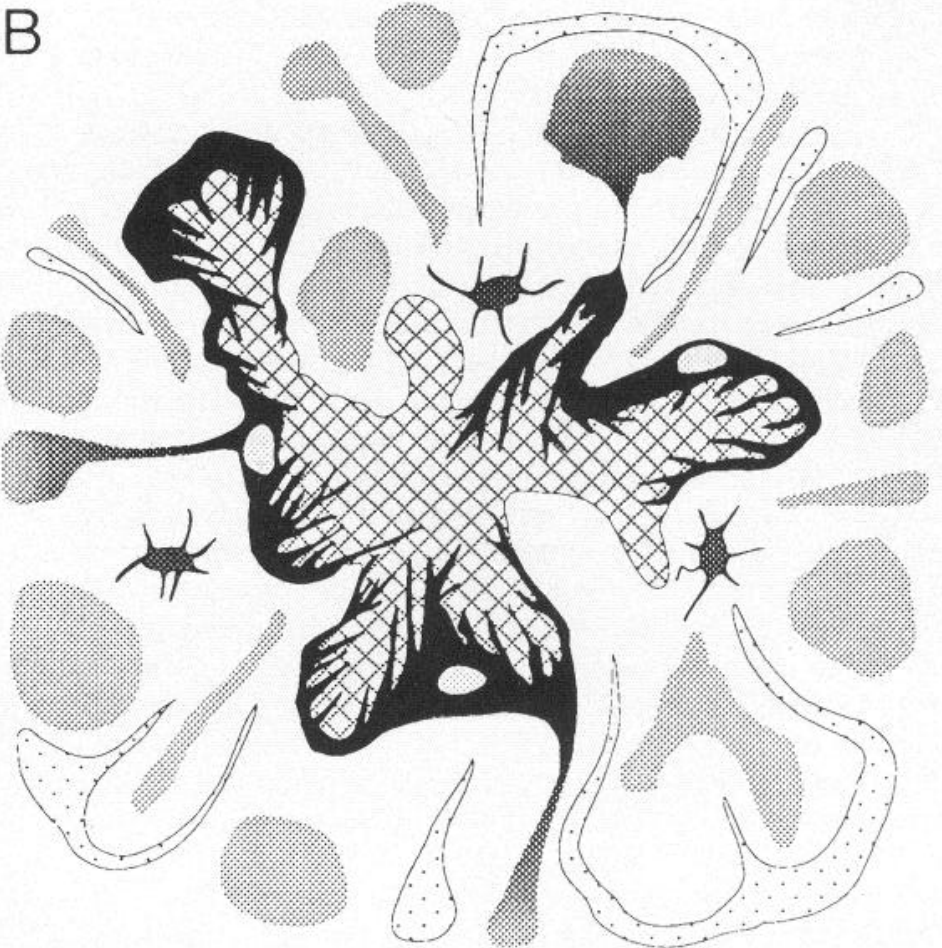

Figure 4. Models of diffuse plaques and neuritic plaques. A, Diffuse plaques are proposed to be filled with fine membranous processes extending from cells (neurons or other) inside the plaque. These membranous as well as intracellular membranous processes are stained with anti-PKC $(\beta \mathrm{II})$ and are different from neurites immunolabeled with anti-tau antibodies. $B$, Fine neuritic processes stained with anti-PKC $(\beta I I)$, contiguous with anti-neurofilament-positive structures, penetrate the center portion of neuritic plaques. These processes are different from typical anti-tau-positive neurites present farther away from the neuritic plaque center. Astroglial and microglial components are also found in neuritic plaques.

ciated changes that may be involved in $\mathrm{AD}$ pathogenesis but precede $\mathrm{AD}$ symptoms. Thus, it is possible that the nondemented samples with cortical plaques that we studied are from individuals who might have developed AD had they lived longer.

A PKC-related alteration is correlated with neuritic plaque formation and not with neurofibrillary tangle formation. Although the identity of P86, the major PKC substrate, is yet to be determined, P86 meets all of the biochemical criteria for MARCKS (myristoylated alanine-rich C-kinase substrate) protein (Stumpo et al., 1989). An anti-MARCKS protein antibody stains the neuritic plaques with the pattern indistinguishable from anti-PKC( $\beta$ II) staining (Saitoh et al., 1991). The other PKC substrate, GAP-43, has recently been localized to neuritic plaques as well (Masliah et al., 1991a). The association of PKC-related changes with neuritic plaque formation is in contrast to our previous finding that the elevated levels of $M_{r} 60,000$ protein (P60) phosphorylation are positively correlated with tangle numbers, and that $\mathrm{P} 60$ phosphorylation levels in $\mathrm{AD}$ cases without tangles are comparable to those of normal cases (Saitoh et al., 1988). The identity of P60 awaits elucidation, although this protein is phosphorylated without PKC activation and is suggested to contain phosphotyrosine (Shapiro et al., 1991). Furthermore, tangles are immunostained with an anti-CK-II antibody but not with anti-PKC antibodies (Iimoto et al., 1990; Masliah et al., 1990). Additionally, recent studies have suggested that Alz-50 antigen, typically found in tangles, is associated with the PKC-independent phosphorylation of tau in AD (Uéda et al., 1990; Lee et al., 1991). Therefore, it is conceivable that the molecular changes involved in plaque formation and in tangle formation are quite distinct. The involvement of phosphorylation cascade reactions in both plaque and tangle formation, however, suggests the possible interaction of these two signal transduction pathways in AD (Saitoh et al., 1991). The finding presented here that a PKC-related cascade is involved in the early stage of the disease might help elucidate the hierarchy of signal transduction changes in AD.

Immunoelectron microscopic studies of diffuse plaques in the neocortex and cerebellum have shown that these lesions contain small, scattered bundles of amyloid among focally blurred membranes of cell processes (Dickson et al., 1990; Yamaguchi et al., 1990). The present study demonstrates that the amyloid-related structures in the diffuse plaques are contiguous with antiPKC $(\beta$ II)- and anti-neurofilament-positive processes derived from neurons located near the diffuse amyloid deposits. This result is consistent with previous electron microscopic studies with AD biopsy tissue that showed an intimate association between the amyloid fibers and the plasma membrane of abnormal neuronal processes (Powers and Skeen, 1988). Furthermore, studies in the aged monkey have pointed to an early neuritic involvement that precedes amyloid deposition (Cork and Price, 1990). No microglial or astroglial processes were found to be associated with the $\mathrm{PKC}(\beta \mathrm{II})$-positive processes in the diffuse plaque, consistent with in vitro data that the majority of cultured microglia or astroglia are anti-PKC $(\beta$ II) negative (Masliah et al., 1991b). Recent immunohistochemical and immunoelectron microscopic studies have described a loose association of microglial processes with the diffuse plaques, but they were not 
specifically concentrated in the diffuse plaques (Itagaki et al., 1989; Rozemuller et al., 1989; Wisniewski et al., 1989; Cras et al., 1990; Mattiace et al., 1990).

How can we interpret the PKC association with neuritic plaque amyloid? The precursor of the major constituent of plaque amyloid (APP, amyloid $\beta$ /A4-protein precursor) has been reported to be phosphorylated by $\mathrm{PKC}$, and it has been suggested that the APP phosphorylation by PKC affects the metabolism of APP (Gandy et al., 1988; Buxbaum et al., 1990). Alternatively, it is also possible that $\mathrm{PKC}$ regulates proteases responsible for APP degradation to amyloidogenic products. Because amyloidogenesis from APP requires its proteolytic degradation, altered PKC activity or localization might promote this process. $\mathrm{Re}-$ cently, we and others have demonstrated that stimulation of various cells increases APP release in the culture medium. For example, the treatment of PC1 2 cells with basic fibroblast growth factor and NGF, possibly through PKC activation, increases the APP levels in the culture medium (Refolo et al., 1989; Schubert et al., 1989). Stimulation of human platelets with thrombin, an activator of PKC, releases APP (Bush et al., 1990; Cole et al., 1990; Van Nostrand et al., 1990). It has been reported that some isoforms of APP contain the protease inhibitor sequence (Kitaguchi et al., 1988; Ponte et al., 1988; Tanzi et al., 1988) and are identical to the protease inhibitor protein nexin II (PN-II) (Oltersdorf et al., 1989; Van Nostrand et al., 1989). Therefore, the stimulation of APP release around diffuse plaques from neurons, which is supported by elevated local levels or an increase in the specific activity of $\mathrm{PKC}(\beta \mathrm{II})$ and stimulated by a still-unknown extracellular stimulus, may disturb the protease/ protease inhibitor balance and help amyloid deposits accumulate. Recent studies have demonstrated the accumulation of APP or its fragment in globular neurites within plaques adjacent to anti- $\beta$ /A4-reactive amyloid (Cole et al., 1991, and references therein; Martin et al., 1991).

In the present study, one previously unanswered question as to the localization of $\mathrm{PKC}(\beta \mathrm{II})$ in the core of neuritic plaques was solved. Consistent with previously reported findings (Masliah et al., 1990), anti-PKC $(\beta I I)$ immunostained the core portion of neuritic plaques, leaving the possibility that anti-PKC $(\beta I I)-$ reactive material might be deposited extracellularly. The components immunostained by anti-PKC $(\beta \mathrm{II})$ are different from the amyloid that is stained by anti- $\beta / \mathrm{A} 4$-protein or the classical neuritic components of plaques that are stained by anti-PKC $(\beta \mathrm{I})$, anti-CK-II, anti-PHF, anti-ubiquitin, or Alz-50. The results in this article clearly demonstrate that the core portion of the plaque is not the mere mass of amyloid but is penetrated by neuronal processes immunopositive with anti-PKC $(\beta \mathrm{II})$ at the membrane (Fig. 4). It is yet to be determined whether these fine neuronal processes penetrating into the amyloid deposit are a continuum of the surrounding neuritic components. The presence of anti$\mathrm{PKC}(\beta \mathrm{II})$-positive neurons and processes in diffuse plaques suggests that fine neuronal processes that penetrate the core portion of classical neuritic plaques are from nearby neurons, whereas dilated axonal terminals and dendrites are from distant neurons (Probst et al., 1989). The three-dimensional reconstruction of electron microscopic images is in progress in our laboratory to answer these questions.

In conclusion, $\mathrm{PKC}(\beta \mathrm{II})$ immunoreactivity is structurally associated with diffuse plaques. Classical neuritic alterations, most clearly detected by PHF markers and glial participation, are found only in neuritic plaques, not in diffuse plaques. Furthermore, the PKC-dependent phosphorylation of P86 and the
PKC $(\beta I I)$ distribution are altered in the cortex of nondemented individuals with cortical diffuse plaques. Therefore, we suggest that a PKC aberration precedes clinical deficits in AD and correlates with neuritic plaque formation but not with neurofibrillary tangle formation. Future research toward the elucidation of mechanisms by which PKC participates in aberrant processing of the APP or amyloidogenesis will help in understanding the pathogenesis of $\mathrm{AD}$ and in developing therapeutic stratcgics to intervene with the progression of $\mathrm{AD}$.

\section{References}

Bush AI, Martins RN, Rumble B, Moir R, Fuller S, Milward E, Currie J, Ames D, Weidemann A, Fischer P, Multhaup G, Beyreuther K, Masters CL (1990) The amyloid precursor protein of Alzheimer's disease is released by human platelets. J Biol Chem 265:15977-15983.

Buxbaum JD, Gandy SE, Cicchetti P, Ehrlich ME, Czernik AJ, Fracasso RP, Ramabhadran TV, Unterbeck AJ, Greengard P (1990) Processing of $\Lambda$ lzheimer $\beta / \Lambda 4$ amyloid precursor protein: modulation by agents that regulate protein phosphorylation. Proc Natl Acad Sci USA 87:6003-6006.

Cole G, Dobkins KR, Hansen LA, Terry RD, Saitoh T (1988) Decreased levels of protein kinase $C$ in Alzheimer brain. Brain Res 452: 165-174.

Cole GM, Galasko D, Shapiro IP, Saitoh T (1990) Stimulated platelets release amyloid $\beta$-protein precursor. Biochem Biophys Res Commun 170:288-295.

Cole GM, Masliah E, Shelton ER, Chan HW, Terry RD, Saitoh T (1991) Accumulation of amyloid precursor fragment in Alzheimer plaques. Neurobiol Aging 12:85-91.

Cork LC, Price DL (1990) Relationships of abnormal neuronal processes and amyloid in plaques in aged monkeys. J Neuropathol Exp Neurol 49:309.

Cras P, Kawai M, Siedlak S, Galloway P, Lower D, Altman RA, Greenberg B, Perry G (1990) Cellular elements involved in amyloid deposition in the senile plaque. J Neuropathol Exp Neurol 49:334.

Dickson DW, Wertkin A, Mattiace LA, Fier E, Kress Y, Davies P, Yen S-H (1990) Ubiquitin immunoelectron microscopy of dystrophic neurites in cerebellar senile plaques of Alzheimer's disease. Acta Neuropathol (Berl) 79:486-493.

Gandy S, Czernik AN, Greengard P (1988) Phosphorylation of Alzheimer disease amyloid precursor peptide by protein kinase $C$ and $\mathrm{Ca}^{++} /$calmodulin-dependent protein kinase II. Proc Natl Acad Sci USA 85:6218-6621.

Giaccone G, Tagliavini F, Linoli G, Bouras C, Frigerio L, Frangione B, Bugiani O (1989) Down patients: extracellular preamyloid deposits precedc neuritic degencration and senile plaquc. Ncurosci Lett 97:232-238

Iimoto DS, Masliah E, DeTeresa R, Terry RD, Saitoh T (1990) Aberrant casein kinase II in Alzheimer's disease. Brain Res 507:273280.

Ikeda K, Haga C, Kosaka K, Oyanagi S (1989) Senile plaque-like structures: observation of a probably unknown type of senile plaque by periodic-acid methenamine silver (PAM) electron microscopy. Acta Neuropathol (Berl) 78:137-142.

Ishii T, Kametani F, Haga S, Sato M (1989) The immunohistochemical demonstration of subsequences of the precursor of the amyloid A4 protein in senile plaques in Alzheimer's disease. Neuropathol Appl Neurobiol 15:135-147.

Itagaki S, McGeer PL, Akiyama H, Zhu S, Selkoe D (1989) Relationship of microglia and astrocytes to amyloid deposits of Alzheimer disease. J Neuroimmunol 24:173-182.

Joachim CL, Morris JH, Selkoe DJ (1989) Diffuse senile plaques occur commonly in the cerebellum in Alzheimer's disease. Am J Pathol 135:309-319.

Kitaguchi N, Takahashi Y, Tokushima Y, Shiojiri S, Ito H (1988) Novel precursor of Alzheimer's disease amyloid protein shows protease inhibitory activity. Nature 331:530-532.

Lee VM-Y, Balin BJ, Otvos L, Trojanowski JQ (1991) A68 proteins are major subunits of Alzheimer disease paired helical filaments and derivatized forms of normal tau. Science 251:675-678.

Love S, Saitoh T, Quijada S, Cole GM, Terry RD (1988) Alz-50, ubiquitin and tau immunoreactivity of neurofibrillary tangles, Pick bodies and Lewy bodies. J Neuropathol Exp Neurol 47:393-405. 
Mann DMA, Esiri MM (1988) The site of the earliest lesions of Alzheimer's disease. N Engl J Med 318:789-790.

Martin LJ, Sisodia SS, Koo EH, Cork LC, Dellovade TL, Weidemann A, Beyreuther K, Masters C, Price DL (1991) Amyloid precursor protein in aged nonhuman primates. Proc Natl Acad Sci USA 88: 1461-1465.

Masliah E, Cole G, Shimohama S, Hansen LA, DeTeresa R, Terry RD, Saitoh T (1990) Differential involvement of protein kinase $C$ isozymes in Alzheimer's disease. J Neurosci 10:2113-2124.

Masliah E, Mallory M, Hansen LA, Alford M, Albright ' 1 , De'Teresa R, Terry RD, Baudier J, Saitoh T (1991a) Patterns of aberrant sprouting in Alzheimer's disease. Neuron, in press.

Masliah E, Yoshida K, Shimohama S, Gage FH, Saitoh T (1991b) Differential expression of protein kinase $C$ isozymes in rat glial cell cultures. Brain Res, in press.

Mattiace LA, Davies P, Dickson DW (1990) Detection of HLA-DR on microglia in the human brain is a function of both clinical and technical factors. Am J Pathol 136:1101-1114.

Motte J, Williams RS (1989) Age-related changes in the density and morphology of plaques and neurofibrillary tangles in Down syndrome brain. Acta Neuropathol (Berl) 77:535-546.

Ogomori I, Kitamoto T, Tateishi J, Sato Y, Suetsugu M, Mitsumasa A (1989) $\beta$-Protein amyloid is widely distributed in the central nervous system of patients with Alzheimer's disease. Am J Pathol 134:243251.

Oltersdorf T, Fritz LC, Schenk DB, Lieberburg I, Johnson-Wood KL, Beattie EC, Ward PJ, Blacher RW, Dovey HF, Sinha S (1989) The secreted form of the Alzheimer's amyloid precursor with the Kunitz domain is protease nexin-II. Nature 341:144-147.

Ponte P, Gonzalez-De Whitt P, Shilling J, Miller J, Hsu D, Greenberg B, Davis K, Wallace W, Lieberburg L, Fuller F, Cordell B (1988) A new $\mathrm{A} 4$ amyloid mRNA contains a domain homologous to scrine proteinase inhibitors. Nature 331:525-527.

Powers JM, Skeen JT (1988) Ultrastructural heterogeneity in cerebral amyloid in Alzheimer's disease. Acta Neuropathol (Berl) 76:613-623.

Probst A, Anderton BH, Brion JP, Ulrich J (1989) Senile plaque neurites fail to demonstrate anti-paired filament and anti-microtubule-associated protein-tau immunoreactive proteins in the absence of neurofibrillary tangles in the neocortex. Acta Neuropathol (Berl) 77:430-436

Refolo LM, Salton SR, Anderson JP, Mehta P, Robakis NK (1989) Nerve and epidermal growth factors induce the release of the Alzheimer amyloid precursor from PC 12 cell cultures. Biochem Biophys Res Commun 164:664-670.

Rozemuller JM, Eikelenboom P, Pals ST, Stam FC (1989) Microglial cells around amyloid plaques in Alzhcimcr's discase express leucocyte adhesion molecules of the LFA-1 family. Neurosci Lett 101:288-292.

Saitoh T, Hansen LA, Dobkins KR, Terry RD (1988) Increased $M_{r}$ 60,000 protein phosphorylation is correlated with neocortical neurofibrillary tangles in Alzheimer's disease. J Neuropathol Exp Neurol 47:1-8.
Saitoh T, Masliah E, Jin L-W, Cole GM, Wieloch T, Shapiro IP (1991) Protein kinases and phosphorylation in neurological disorders and cell death. Lab Invest 64:596-616.

Schubert D, Jin L-W, Saitoh T, Cole G (1989) The regulation of amyloid $\beta$ protein precursor secretion and its modulatory role in cell adhesion. Neuron 3:689-694.

Shapiro IP, Masliah E, Saitoh T (1991) Altered protein tyrosine phosphorylation in Alzheimer's disease. J Neurochem 56:1154-1162.

Stumpo DJ, Graff JM, Albert KA, Greengard P, Blackshear PJ (1989) Molecular cloning, characterization, expression of a cDNA encoding the "80- to $87-\mathrm{kDa}$ " myristoylated alanine-rich $\mathrm{C}$ kinase substrate: a major cellular substrate for protein kinase C. Proc Natl Acad Sci USA 86:4012-4016.

Tagliavini F, Giaccone G, Frangione B, Bugiani O (1988) Preamyloid deposits in the cerebral cortex of patients with Alzheimer's disease and nondemented individuals. Neurosci Lett 93:191-196.

Tanzi RE, McClatchey AI, Lamperti ED, Villa-Komaroff L, Gusella JF, Neve RL (1988) Protease inhibitor domain encoded by an amyloid protein precursor mRNA associated with Alzheimer's disease. Nature 331:528-530.

Terry RD, Hansen LA, DeTeresa R, Davies P, Tobias H, Katzman R (1987) Senile dementia of the Alzheimer type without neocortical neurofibrillary tangle. J Neuropathol Exp Neurol 46:262-268.

Ueda K, Masliah E, Saitoh T, Bakalis SL, Scoble H, Kosik KS (1990) Alz-50 recognizes a phosphorylated epitope of tau protein. J Neurosci $10: 3295-3304$

Van Nostrand WE, Wagner SL, Suzuki M, Choi BH, Farrow JS, Geddes JW, Cotman CW, Cunningham DD (1989) Protease nexin-II, a potent anti-chymotrypsin, shows identity to amyloid $\beta$ protein. $\mathrm{Na}$ ture 341:546-548.

Van Nostrand WE, Schmaier AH, Farrow JS, Cunningham DD (1990) Protease nexin II (amyloid $\beta$-protcin precursor): a platclct $\alpha$-granulc protein. Science 248:745-748.

Wisniewski H, Terry RD (1973) Re-examination of the pathogenesis of senile plaque. Prog Neuropathol 2:1-26.

Wisniewski HM, Wegiel J, Wang KC, Kujawa M, Lach B (1989) Ultrastructural studies of the cells forming amyloid fibers in classical plaques. Can J Neurol Sci 16:535-542.

Yamaguchi H, Hirai S, Morimatsu M, Shoji M, Ihara Y (1988) A variety of cerebral amyloid deposits in the brains of the Alzheimertype dementia demonstrated by $\beta$-protein immunostaining. Acta Neuropathol (Berl) 76:541-549.

Yamaguchi H, Nakazato Y, Hirai S, Shoji M (1989) Immunoelectron microscopic localization of amyloid beta protein in the diffuse plaques of Alzheimer-type dementia. Brain Res 508:320-324.

Yamaguchi H, Nakazato Y, Hirai S, Shoji M, Harigaya Y (1990) Electron micrograph of diffuse plaques. Initial stage of senile plaque formation in the Alzheimer brain. Am J Pathol 135:593-597. 